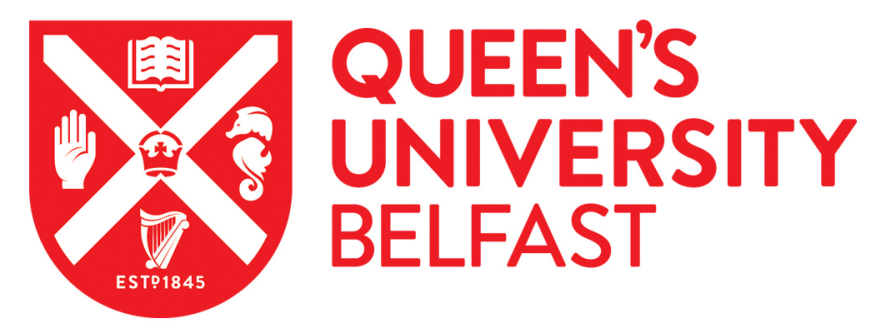

\title{
Developing product recall capability through supply chain quality management
}

Zhang, M., Hu, H., \& Zhao, X. (2020). Developing product recall capability through supply chain quality management. International Journal of Production Economics. https://doi.org/10.1016/j.ijpe.2020.107795

\section{Published in:}

International Journal of Production Economics

\section{Document Version:}

Peer reviewed version

Queen's University Belfast - Research Portal:

Link to publication record in Queen's University Belfast Research Portal

\section{Publisher rights}

Copyright 2020 Elsevier.

This manuscript is distributed under a Creative Commons Attribution-NonCommercial-NoDerivs License

(https://creativecommons.org/licenses/by-nc-nd/4.0/), which permits distribution and reproduction for non-commercial purposes, provided the author and source are cited.

\section{General rights}

Copyright for the publications made accessible via the Queen's University Belfast Research Portal is retained by the author(s) and / or other copyright owners and it is a condition of accessing these publications that users recognise and abide by the legal requirements associated with these rights.

Take down policy

The Research Portal is Queen's institutional repository that provides access to Queen's research output. Every effort has been made to ensure that content in the Research Portal does not infringe any person's rights, or applicable UK laws. If you discover content in the Research Portal that you believe breaches copyright or violates any law, please contact openaccess@qub.ac.uk. 


\title{
Developing product recall capability through supply chain quality management
}

\begin{abstract}
Supply chain quality management (SCQM) has been viewed as a critical method for a manufacturer's management of product recalls. This study aims to empirically investigate the impact of SCQM practices on product recall capability using a sensemaking perspective. We adopt a multi-method approach by combining case study and quantitative survey methods. This study selects three manufacturers from the food, automobile and pharmaceutical industries to conduct an explorative case study. The findings reveal that product recall capability includes tracking and traceability and formal process, and the manufacturers use quality management teamwork, supplier qualification and supplier involvement as the key SCQM practices. A conceptual framework of the relationships between SCQM practices and product recall capability is developed based on the findings of the case study. The hypotheses are empirically tested using structural equation modelling, bootstrapping method and data collected from 400 manufacturers in China. We find that quality management teamwork and supplier qualification are positively associated with product recall capability. Quality management teamwork is positively associated with supplier qualification and involvement. In addition, supplier qualification partially mediates the effect of quality management teamwork and fully mediates the effect of supplier involvement on product recall capability.
\end{abstract}

Keywords: product recall, supply chain quality management, multi-method research, sensemaking 


\section{Introduction}

A product recall involves repairing or removing a product that has been found to be hazardous to consumers from the market (Smith et al., 1996, Roth et al., 2008). Reports show that product recalls are on the rise (Marucheck et al., 2011). For example, the European recall \& notification index reveals that the recalls of consumer products increased by $17.2 \%$, reaching 483 , and those of food and beverages increased by 7.1\%, reaching 1041, in the first quarter of 2019 (StericycleExpertSolution, 2019). Empirical evidence shows that product recalls are associated with a negative stock market reaction (Wood et al., 2017, Ni et al., 2016). Failing to recall defective products quickly and efficiently leads to life-threatening risks to consumers and damages firms' brand image, reputation and market value (Wowak and Boone, 2015, Hora et al., 2011). Product recalls are frequently connected to suppliers and subcontractors located in emerging economies, such as China (Zhao et al., 2013, Lyles et al., 2008, Marucheck et al., 2011). For example, China was the top country of origin for consumer product (327) and food (71) recalls in Europe (StericycleExpertSolution, 2019). The number of recalls in the USA involving Chinese-made toys has also been on the rise over the last few years (Beamish and Bapuji, 2008). Therefore, a deep understanding of Chinese manufacturers' quality management practices and capabilities to manage product recalls is critical for global companies to recall products quickly and efficiently (Lyles et al., 2008).

The objective of this study is to empirically investigate the impact of supply chain quality management (SCQM) practices on product recall capability. This study defines product recall capability as a manufacturer's ability to take actions to provide repairs or remove a product from the market quickly and effectively (Smith et al., 1996, FDA, 2009). Quality management includes a set of mutually reinforcing principles, each of which is supported by a set of practices and techniques (Sousa and Voss, 2002). Researchers argue that quality management can improve quality performance and reduce product defects (Anderson et al., 1994, Sousa and Voss, 2002). Quality management emphasizes internal and external cooperation (Anderson et al., 1994); hence, companies can pursue supply chain and quality goals (e.g., customer satisfaction and integration) simultaneously (Flynn and Flynn, 2005). SCQM refers to the collaboration among an organization's internal functions and with external supply chain partners and the joint management of intra- and inter-organisational quality-related processes (Robinson and Malhotra, 2005, Huo et al., 2014). It adopts a system-level perspective to actively manage quality in supply chains (Yeung, 2008, Flynn and Flynn, 2005), which involves integrating internal resources and cooperating with suppliers (Zhang et al., 2019). 
Researchers have proposed various SCQM frameworks that include different practices (Foster, 2008, Lo and Yeung, 2006, Robinson and Malhotra, 2005). Empirical evidence also reveals that various SCQM practices have different effects on performance outcomes (Huo et al., 2014, Zhang et al., 2019, Lin et al., 2005). However, few studies have linked SCQM practices with product recall capability. Moreover, it is difficult for researchers to directly observe and measure product recall capability (Chen et al., 2009). The current understanding of product recalls is still in its infancy (Wowak and Boone, 2015), and there is limited empirical evidence of Chinese manufacturers' product recall capability. The first research question addressed by this paper is what are the components of product recall capability and the SCQM practices adopted by Chinese manufacturers?

Product harm crises are among a manufacturer's worst nightmares (Wowak and Boone, 2015, Yao and Parlar, 2019). They can trigger sensemaking and drive the manufacturer to take appropriate courses of action (Maitlis and Christianson, 2014). Sensemaking is the process by which actors engage in ongoing circumstances by extracting cues and making plausible sense retrospectively while enacting order into those ongoing circumstances (Weick et al., 2005). Product failures may place manufacturers in turbulent situations that are ambiguous and violate expectations (Marucheck et al., 2011). Hence, sensemaking becomes critical because it helps manufacturers make sense of equivocal information and create a supply chain environment to manage product recalls (Weick, 1995, Wowak and Boone, 2015). SCQM practices, such as creating multifunctional teams and establishing collaborative relationships with suppliers for quality management (Lin et al., 2005, Foster, 2008), allow employees to make sense of quality failures (Weick, 1995). It also plays critical roles in reducing the equivocality of the information obtained from globalized and multi-tier supply chains involving offshore suppliers. Therefore, a sensemaking perspective can shed light on how SCQM practices help manufacturers interpret product failures and modify their actions in developing product recall capability (Wowak and Boone, 2015, Weick, 1979). The second research question addressed by this paper is what is the impact of SCQM practices on product recall capability?

Empirical investigation of the relationships between SCQM practices and product recall capability is important for three reasons. First, it enhances existing knowledge of the practices adopted by Chinese manufacturers to manage quality and product recalls. Lyles et al. (2008) highlight that supply chain management plays a critical role in China's product recall problems. Roth et al. (2008) develop a conceptual framework of SCQM by analysing global food supply chains and the product recalls originating in China. Marucheck et al. (2011) analyse the product safety issues in five industries and identify supplier relationships and traceability as key 
challenges in manging product recalls. Sousa and Voss (2001) argue that quality management is context dependent. Using a multi-method approach, this study advances extant conceptual studies by providing empirical evidence of the components of product recall capability and the SCQM practices used by Chinese manufacturers (Lyles et al., 2008, Roth et al., 2008). The results build a foundation for researchers to empirically investigate the antecedents and consequences of product recall capability (Wowak and Boone, 2015).

Second, this study clarifies the impact of SCQM practices on product recall capability. In a literature review, Wowak and Boone (2015) argue that statistical process control and total quality management are precursors of product recall. They further highlight that sensemaking and enactment is a promising underutilized theory in product recall research. Huo et al. (2014) find that internal quality integration enhances supplier quality integration, and both enhance product quality. Song et al. (2017) report that intra- and inter-SCQM has a positive effect on food safety and quality using data collected from Chinese food companies. Using a sensemaking perspective, this study extends existing studies by revealing that SCQM practices are critical antecedents for manufacturers to develop product recall capability (Wowak and Boone, 2015). The results provide insights into the interrelationships among quality management practices and their joint effects on performance outcomes (Song et al., 2017, Huo et al., 2014).

Third, this study reveals that a manufacturer can develop product recall capability by adopting SCQM practices. The findings thus provide guidelines for Chinese manufacturers on how to apply quality management practices and make investment decisions for developing product recall capability (Wowak and Boone, 2015). The findings can also help global companies effectively manage product recalls in the supply chains passing through China by collaborating and partnering with Chinese manufacturers with high product recall capability (Lyles et al., 2008, Roth et al., 2008).

The next section reviews the literature on product recall, product recall capability and SCQM and then introduces the sensemaking perspective. Section 3 discusses the research methods. We adopt a multi-method approach by combining case study and quantitative survey methods. Section 4 presents the findings of the case study and quantitative survey. We discuss the empirical findings, highlight the theoretical and practical implications, and point out the limitations and future research directions in section 5 .

\section{Literature review and theoretical background}

\subsection{Product recall and product recall capability}


Product recalls occur when manufacturers' products violate safety standards, fail to conform to specifications or contain defects that could cause substantial harm (Chen et al., 2009, Marucheck et al., 2011). One stream of studies empirically investigates the financial impact of product recalls and the factors affecting the impact. The findings reveal that product recalls result in negative abnormal returns (e.g., Zhao et al., 2013, Ni et al., 2016, Wood et al., 2017). Researchers further reveal that the degree of the impact is affected by recall strategy (Zhao et al., 2013), degree of hazard (Ni et al., 2016), operational characteristics (e.g., time to recall, inventory slack and product scope) and firm characteristics (e.g., sales, growth prospects, capital structure and diversification) (Wood et al., 2017). Another stream of studies empirically explores the factors that may affect the likelihood of recalls. The results show that business strategies (research and development focus and broader product portfolios) (Thirumalai and Sinha, 2011), supply chain sourcing strategies (outsourcing, offshoring, and offshore outsourcing) (Steven et al., 2014) and outsourcing to emerging markets (Steven and Britto, 2016) increase product recalls, while prior recall experience (Thirumalai and Sinha, 2011) and sales penetration into emerging markets (Steven and Britto, 2016) reduce product recalls.

Product recall capability allows a manufacturer to identify the sources of quality problems and remove tainted products from circulation (Wowak and Boone, 2015). Traceability is the ability to track a product's flow or attributes throughout the production process and supply chain (Rose et al., 2008). It plays an intricate role in a firm's ability to identify the design flaws and manufacturing defects in supply chains and has been viewed as a key component of product recall capability (Marucheck et al., 2011, Wowak and Boone, 2015). The capabilities of tracing and tracking allow a manufacturer to monitor suppliers to ensure that they have followed the procedures throughout the whole process from the origin to the point of sale (Lyles et al., 2008); hence, they are very useful for preventing hazards, assuring the quality and safety of products and ultimately controlling risks (Marucheck et al., 2011, Alfaro and Rabade, 2009). Therefore, the capabilities of tracing and tracking can provide both qualitative and quantitative benefits and are increasingly important for managing product recalls (Alfaro and Rabade, 2009, Marucheck et al., 2011). In addition, researchers argue that formal processes are essential for firms to quickly and effectively respond to product failures (Wowak and Boone, 2015). For example, Berman (1999) identifies formal processes and planning activities before, during and after product recalls. Kumar and Schmitz (2011) develop processes and measures for reacting to product defects using a Six Sigma DMAIC methodology. Another stream of studies focuses on how to make decisions on timing and remedy in the recall process. The dynamic programming method has been used to determine the optimal timing of product recall (Yao 
and Parlar, 2019). Chen et al. (2009) examine the proactive and passive strategies in responding to product harm crises. Hora et al. (2011) find that time to recall can be reduced when a firm uses a preventive strategy, product defects are caused by manufacturing defects, and supply chain entities are close to end customers. Liu et al. (2016) report that a firm's decision on remedy is jointly influenced by cost, product hazard and the CEO's personal interests.

Researchers have also proposed various capabilities that are critical for managing product recalls in globalized supply chains. For example, Lyles et al. (2008) argue that deep supply chains, relationships, trust and cultural misunderstandings are key supply chain issues related to China's product recall problems. Roth et al. (2008) develop a "Six Ts" framework that proposes that traceability, transparency, testability, time, trust and training are the key capabilities for managing product recalls in food supply chains. Marucheck et al. (2011) identify regulation and standards, product lifecycle management, traceability and recall management and supplier relationships as the key challenges for managing product recalls. Ketchen et al. (2014) identify four types of product recalls and argue that they require different resource endowments and resource orchestration capabilities. However, there is limited empirical evidence on product recall capability and how to develop the capability, especially for manufacturers in emerging markets. This is echoed by the literature review of Wowak and Boone (2015), which identifies recall precursors, recall process, impact of recalls and mitigation approaches as the key aspects of product recall research.

\subsection{Supply chain quality management}

SCQM extends the firm-centric quality management approaches to a supply chain perspective, allowing a manufacturer to leverage internal and supply chain partners' resources and capabilities to achieve high levels of quality-related performance at low costs (Flynn and Flynn, 2005, Foster, 2008). Through creating an integrated quality system to synchronize decisions and activities and building cooperative relationships in a supply chain, SCQM helps a manufacturer manage quality failures in a globally dispersed supply chain (Robinson and Malhotra, 2005, Yeung, 2008). One stream of studies focuses on identifying SCQM practices. Researchers have proposed various frameworks to conceptualize SCQM. Some scholars focus on supplier quality management (Lo and Yeung, 2006), while others consider both supplier and internal quality management practices. For example, Lin et al. (2005) conceptualize SCQM as internal quality practices and supplier participation and supplier selection. Robinson and Malhotra (2005) argue that SCQM includes both intra-organisational coordination focusing on internal operations and inter-organisational integration focusing on suppliers. Foster (2008) identifies quality practices and supplier relations as common themes in SCQM. Lin et al. (2013) 
find that the strategic content variables of SCQM include training programs, ISO initiatives and supplier quality audit programmes.

Another stream of studies empirically investigates the effects of SCQM on performance outcomes and the relationships among SCQM practices. For example, Lo et al. (2007) report that supplier quality management improves quality performance. Yeung (2008) finds that quality management is positively associated with strategic supply management, which then improves operational and business performance. Lin et al. (2005) report that quality management practices, supplier participation and supplier selection are correlated with each other, and supplier participation is positively associated with organizational performance. Kaynak and Hartley (2008) find that supplier quality management, which is conceptualized as quality-based supplier selection and evaluation and supplier assistance in product development, is positively related to quality performance. Song et al. (2017) show that intra- and inter-SCQM enhance a food company's export performance and that the effects are mediated by food certification. Zhang et al. (2019) find that internal quality integration is positively associated with supplier quality integration and that both improve competitive performance. Therefore, the empirical evidence reveals that internal and supplier quality management practices improve a manufacturer's quality performance and that the former enhances the latter. However, few studies have explored the impact of SCQM practices on product recall capability.

\subsection{Theoretical background}

Sensemaking refers to the process through which employees work to understand unexpected or ambiguous events and take actions accordingly (Weick, 1995). It provides a perspective to explain how organizations cope with interruptions by interpreting cues from an environment and producing part of the environment they face. Weick (1995) argues that sensemaking is social, ongoing, enactive of sensible environments, and focused on and by extracted cues. During sensemaking, an organization can influence environments through enactment, which refers to the process in which organization members create a stream of events to shape the environment (Weick, 1979). The information an organization receives differs in terms of equivocality. Information equivocality refers to situations in which organizations face the choice of two or more alternative interpretations of the information obtained from the environment (Maitlis and Christianson, 2014). Weick (1979) proposes that an organization can reduce equivocality by sensemaking.

A sensemaking perspective provides insights into how manufacturers derive meaning from product failures and develop product recall capability (Wowak and Boone, 2015). Product harm crises are normally high-impact events that threaten the profitability and even the survival 
of manufacturers (Marucheck et al., 2011). Responding to product failures requires manufacturers to process equivocal information that is normally ambiguous about the causes of product defects and creates uncertainty on how to act (Roth et al., 2008, Weick et al., 2005). Sensemaking occurs in organizations when members confront events and issues that are surprising and confusing, and hence, it starts with chaos and crises (Weick, 1995). Thus, product harm crises stimulate sensemaking, through which manufacturers interpret the cues from supply chains and adjust actions accordingly (Wowak and Boone, 2015, Maitlis and Christianson, 2014). Therefore, we argue that a manufacturer's product recall capability includes the capability of obtaining information that facilitates the interpretation of product failures and the capability of responding to product defects quickly.

We argue that SCQM practices enable a manufacturer to develop a sensemaking process to build product recall capability. These practices allow manufacturers to interpret cues from supply chains and enact changes in their supply chains. Organizations can reduce equivocality by creating committees and teams to handle specific information (Weick, 1995). Quality management teamwork is the practice of using teamwork in problem solving and quality improvement (Huo et al., 2014). It allows employees from different departments to analyse and discuss product quality and share their past experiences and best practices on managing product recalls together (Huo et al., 2014). Teamwork also provides a channel for employees in different departments to communicate with each other and develop collaborative relationships and commitment for quality improvement (Lo et al., 2007, Flynn and Flynn, 2005). Quality management teamwork provides a way for employees to interpret the cues extracted by product failures and from the supply chain environment. The practice also creates a social context and promotes ongoing communications among employees for the retrospective analysis of past product recalls. Therefore, quality management teamwork promotes sensemaking.

Actively managing suppliers can shape the supply chain environment for making sense of product recalls (Weick, 1995). As a result, manufacturers adopt supplier quality management practices to create a supply chain that facilitates sensemaking and reduces equivocality (Weick et al., 2005). Product failures may be caused by design or production flaws (Hora et al., 2011). Therefore, we focus on supplier qualification, which refers to the practices of verifying suppliers' capabilities for complying with contract specifications with a reasonable degree of certainty (Wan et al., 2012), and supplier involvement, which refers to the practices that bring together one or more suppliers with a company's product design team in the product development process (van Echtelt et al., 2008). Supplier qualification includes the practices of performance evaluation and quality assessment of suppliers, which ensure that suppliers have 
reliable quality management systems and follow established guidelines and procedures. As a result, qualified suppliers can provide clear and predictable information about their manufacturing processes, reducing production flaws. Collaborating with suppliers in product design promotes communications and the development of a shared language between a manufacturer and suppliers, which reduce information equivocality in the supply chain environment. Suppliers and a manufacturer can also develop a common understanding of product designs, which helps them identify design flaws collaboratively. Therefore, supplier qualification and involvement can shape suppliers' operations to create a supply chain to reduce information equivocality and hence facilitate sensemaking.

\section{Research methods}

This study adopts a multi-method approach (Choi et al., 2016, Boyer and Swink, 2008). There are three reasons for combining case study and quantitative survey methods (Saunders et al., 2009). The first reason is facilitation. The case study method is used to identify elements to measure the constructs and develop hypotheses. The quantitative survey method is then employed to test and refine the hypotheses. This choice is also motivated by the research objectives and the lack of empirical evidence on how Chinese manufacturers develop product recall capability (Voss et al., 2002, Chen et al., 2009). The second reason is generality. The case study method provides an in-depth description of product recall capability and SCQM practices in a natural setting, which provides a context for the quantitative survey (Boyer and Swink, 2008). The quantitative survey enables researchers to measure a manufacturer's product recall capability and SCQM practices, and hence, they can provide a sense of the relative importance of the relationships (Boyer and Swink, 2008). The third reason is triangulation. The quantitative survey allows researchers to validate the findings from case studies. Therefore, combining the two methods helps researchers use two independent sources of data to corroborate research findings (Choi et al., 2016).

\subsection{Phase 1: Case study}

\subsubsection{Data collection}

We conducted a pilot case study of a Chinese toy manufacturer using secondary data (i.e., documentary). This is because empirical evidence reveals that global toy supply chains are experiencing more frequent product recalls, and most of the recalls involve Chinese manufacturers (Hora et al., 2011, Ni et al., 2016, Wood et al., 2017). For example, the percentage of recalls in the USA that involved Chinese-made toys was approximately $80 \%$ 
since 2003 and reached 95\% in 2007 (Beamish and Bapuji, 2008). We found that the manufacturer has implemented a system to track the usage, storage and inspection of paint and other raw materials in supply chains. It has also developed customer complaint and satisfaction management systems for monitoring and responding to quality problems. The manufacturer provided training (e.g., categorization management method) for suppliers who participated in the manufacturer's new product development. Cross-functional teams were used in quality management. Multiple departments were involved when qualifying and collaborating with suppliers.

This study then theoretically selected three manufacturers from the food, automobile and pharmaceutical industries because Chinese manufacturers in these industries play critical roles in global supply chains and have attracted much attention due to quality issues (Lyles et al., 2008, Roth et al., 2008). The three cases were chosen based on literal replication, as they all face stringent government regulations and industrial pressure on quality and have actively managed product recalls and adopted SCQM (Yin, 2009). The unit of analysis is at the firm level, and a description of the three cases is provided in Appendix I.

The data sources for this study included semi-structured interviews, personal observations and secondary data (e.g., information from the internet and company documents), allowing triangulation on important issues (Yin, 2009). The interviews were guided by a research protocol (Appendix II), which was initially developed based on the research questions, relevant literature and the pilot study. The research team, which included five operations management professors and three $\mathrm{Ph} . \mathrm{D}$. students, interviewed the manufacturers and their suppliers. Each interview lasted approximately 2.5 hours and was conducted in Chinese. The informants included general managers, quality managers and purchasing managers in the case companies and their suppliers. The characteristics of the respondents are provided in Appendix II. The interviews were all tape-recorded. The research team was also given a plant tour lasting an hour at each manufacturer. The team members conducted debriefing meetings both before and after each interview to share information and experiences and to review the logic and contents of the interviews to establish a chain of evidence. The case database included transcripts, notes, documents gained from each manufacturer and information from the internet. Reliability was addressed using the research protocol and the development of the case study database (Voss et al., 2002). The use of multiple data sources and the maintenance of a chain of evidence help this study establish construct validity (Voss et al., 2002).

\subsection{Phase 2: Quantitative survey}

\subsubsection{Questionnaire design}


Based on the relevant literature and case study, a survey instrument was designed to measure quality management teamwork, supplier qualification, supplier involvement and product recall capability. A multiple-item 7-point Likert-type scale (1= "strongly disagree"; $2=$ "disagree"; $3=$ "somewhat disagree"; 4= "neutral"; 5= "somewhat agree"; 6= "agree"; 7= "strongly agree") was used for all constructs. For example, manufacturers may have different degrees of tracking and traceability and hence the construct can be evaluated using the Likert scale. Respondents were asked to evaluate several statements. If the respondents believed that manufacturers can only identify and trace some outputs from production to delivery, cannot effectively identify the sources of almost all raw materials and parts for each unit of output, take a long time to identify the sources of quality problems in supply chains, or only have limited access to the information that allows tracking the sources of quality problems in supply chains, their evaluation for the manufacturers' tracking and traceability would be low. As a result, their responses to the corresponding statements would be at the lower end of the scale (1 to 3 ). Otherwise, their answers to the statements would be at the higher end of the scale (5 to 7 ). Moreover, for instance, if a respondent agreed that the manufacturer can identify and trace each unit of output from production to delivery, his/her response to the statement "we can identify and trace each unit of our output from production to delivery" would be 6 . If the respondent somewhat agreed that the company can identify and trace each unit of output from production to delivery, his/her response to the statement would be 5 . In addition, the questionnaire included questions related to the demographic profile of the manufacturers (e.g., industry, ownership, number of employees and total sales). The scales are listed in Appendix III.

Quality management teamwork was measured by five items related to using teamwork in problem solving and quality improvement. Supplier qualification was measured by four items about qualifying suppliers and performance evaluation. Supplier involvement was measured by three items regarding collaborating with suppliers in product design. The items were adopted from the high-performance manufacturing project (Huo et al., 2014, Zhang et al., 2019) and adjusted based on the findings of the case study to reflect the research context. Product recall capability was measured by tracking and traceability and formal process which were developed according to the findings of the case study. The tracking and traceability were measured by four items related to the capabilities to trace materials and products and identify the sources of quality problems. The formal process was measured by three items about the procedures, systems and guidelines for issuing and coordinating product recalls. In addition, we included industry, ownership and total sales as control variables. Three dummy variables were used to capture the four industries, and two dummy variables were used to measure the 
three ownership groups (Table 1). Total sales was operationalized using a Likert scale ranging from 1 to 5 ( $1=$ " $5 \leq 10$ million"; $5=$ " $\geq 100$ million") (Table 1$)$.

The questionnaire was first pilot tested by managers from eight manufacturers who had attended a quality management conference. The research team discussed the questions face-toface with the managers after they filled out the questionnaire and clarified the meaning of the questions with them. When any confusion arose, the wording of the questions was modified. The questionnaire was then tested in a seminar on SCQM by managers from twenty-two manufacturers before its full-scale launch. The questionnaire was further refined based on the resulting feedback and comments.

\subsubsection{Sampling and data collection}

Manufacturing companies were randomly selected from three areas (i.e., Pearl River Delta, Yangtze River Delta and Bohai Sea Economic Area) in China and from four industries (i.e., toy, food, automobile and pharmaceutical). The manufacturing company list of the National Bureau of Statistics of China was used as the sampling frame.

The manufacturing companies were contacted by phone and invited to participate in the project. According to the pilot tests and case study, key informants included general managers, presidents, directors, quality managers and purchasing managers. Questionnaires were sent to 1623 randomly selected manufacturers. The research team finally collected 400 usable questionnaires. Hence, the response rate was $24.6 \%$. Early and late responses were compared in terms of demographic characteristics, including ownership, number of employees and total sales, and the t-statistics showed no significant differences, indicating that non-response bias was not a major concern in this study. The sample demographics are shown in Table 1.

\section{$<<<<<$ Insert Table 1 about here $>>>>>>$}

Since the survey data were obtained from single informants, common method bias might be a concern. Harman's single factor test was conducted using unrotated exploratory factor analysis. The largest percentage of variance explained was $30.4 \%$. Confirmatory factor analysis (CFA), in which the common methods was treated as a single factor loading on all items, was also conducted (Podsakoff et al., 2003). The fit indices were $\chi^{2}(151)=911.60$, comparative fit index $(\mathrm{CFI})=0.69$, Tucker-Lewis index $(\mathrm{TLI})=0.65$ and root mean square error of approximation $(\mathrm{RMSEA})=0.11$, which are unacceptable (Hu and Bentler, 1999). In addition, we used the technique of controlling for the effects of an unmeasured latent methods factor (Podsakoff et al., 2003). Specifically, we built two CFA models. A second-order measurement model (Model A) was constructed using CFA. In the model, the items for product recall capability were linked first to the constructs of tracking and traceability and formal process, 
which were loaded onto the second-order construct product recall capability, and the items for quality management teamwork, supplier qualification and supplier involvement were directly linked to corresponding constructs. The covariance among the constructs was freely estimated. In Model B, items were loaded on their corresponding constructs (like Model A) as well as on a latent common methods variance factor. The significance of the structural parameters was examined in both models. The resulting model fit indices of Model A were $\chi^{2}(143)=235.383$, $\mathrm{CFI}=0.962$, TLI $=0.955$ and RMSEA $=0.040$, and those of Model B improved only marginally compared with Model A $(\Delta \mathrm{CFI}=0.002, \Delta \mathrm{TLI}=0.004$ and $\triangle \mathrm{RMSEA}=0.001)$. Therefore, the fit indices of both models are better than the threshold values recommended by $\mathrm{Hu}$ and Bentler (1999). There were no significant changes in item loadings, and the item loadings were significant in both models. In addition, we took remedies to reduce common method bias when designing the questionnaire and collecting data (MacKenzie and Podsakoff, 2012). First, we made the tasks of responding accurately easier. The questionnaire was designed based on the existing literature and the findings of the case study. Rigorous translations and backtranslations and pilot tests were performed to ensure that the language, vocabulary and syntax we used facilitated understanding among the respondents. Second, to ensure that the respondents had enough knowledge to answer the questions accurately, we contacted each target company and asked them questions about the organizational structure and position statement to identify who was responsible for quality and product recall management before sending out the questionnaire. In the cover letter of the questionnaire, we also emphasized that the respondent to this questionnaire should have an overall understanding of product recall and quality management in the company. If the respondent felt that he/she was not the best person to answer certain questions, he/she was requested to ask the most knowledgeable person to answer them. Third, we increased the motivation to respond accurately. In the cover letter, we highlighted the potential scientific contributions and the benefits of the project to the participants and guaranteed the anonymity of their responses. We also motivated the respondents by providing a reward of $500 \mathrm{RMB}$ and inviting them to an SCQM executive forum free of charge. Fourth, we made it difficult for respondents to satisfice. The questions measuring a construct were put in different sections of the questionnaire. Reverse wording questions were also used to check whether the respondents paid attention to the questions and answered them carefully. Therefore, common method bias is not a serious concern in this study (Podsakoff et al., 2003).

\subsubsection{Reliability and validity}


Reliability was assessed in terms of composite reliability and Cronbach's alpha. The values of composite reliability and Cronbach's alpha range from 0.838 to 0.881 and from 0.708 to 0.829 , respectively (Appendix III), which are all above the recommended threshold value of 0.70 , suggesting adequate reliability (Fornell and Larcker, 1981).

Convergent validity was assessed by the average variance extracted (AVE). All AVE values are above the recommended value of 0.50 (ranging from 0.568 to 0.667 ), which demonstrates adequate convergent validity (Appendix III) (Fornell and Larcker, 1981). In addition, the second-order measurement model was used to assess convergent validity. The model fit indices are $\chi^{2}(143)=235.383, \mathrm{CFI}=0.962$, TLI $=0.955$ and $\mathrm{RMSEA}=0.040$, which are better than the threshold values recommended by $\mathrm{Hu}$ and Bentler (1999). The factor loadings range from 0.623 to 0.863 , and the t-statistics of the factor loadings are all significant at the $p$ $<0.01$ level (Appendix III). Therefore, convergent validity is achieved.

Discriminant validity was assessed by comparing the square roots of the AVE of each construct with the correlations between the focal construct and every other construct. A square root higher than the correlations with other constructs suggests discriminant validity (Fornell and Larcker, 1981). Table 2 shows the mean and standard deviation of the constructs and their correlations. Comparisons of all correlations and square roots of the AVEs on the diagonal indicate adequate discriminant validity for all constructs. Discriminant validity was further assessed by using constrained measurement models for each possible pair of constructs in which the correlation was fixed to 1 . The constrained measurement models were subsequently compared to the original unconstrained measurement model in which the correlations among constructs were freely estimated. In this study, all $\chi^{2}$ differences between the constrained and unconstrained models are significant at the 0.01 level. As such, discriminant validity is achieved.

\section{$<<<<<$ Insert Table 2 about here $>>>>>>$}

We further examined the second-order latent construct (product recall capability) following the methods suggested by Crede and Harms (2015). We compared the second-order model with four alternative models and found that it can reproduce the covariation among manifest variables as accurately as the less parsimonious alternative models (i.e., bi-factor and oblique first-order models) and better than the more parsimonious alternative models (i.e., single-factor and orthogonal first-order models). We examined the effect size of the second-order model by calculating the target coefficient, relative normed-fit index and RMSEA-P. The findings indicate that the second-order model can reproduce the covariation among first-order factors. The AVE (0.923) of the second-order model reveals that the second-order factor can explain 
substantial variation in first-order factors. Moreover, the average amount of variance in manifest variables that can be explained by the second-order construct $(54.0 \%)$ and the variance of each manifest variable explained by the second-order construct (ranging from $38.3 \%$ to $69.1 \%$ ) indicate that the second-order factor can explain substantial variation in the manifest variables. Therefore, the empirical evidence suggests that product recall capability is a second-order latent construct.

\section{Analysis and results}

\subsection{Case study findings}

Purposive coding was used to identify instances of product recall capability and SCQM practices (Appendix IV) (Voss et al., 2002). The research team individually coded the case materials and met to discuss the classifications. If there were disagreements, the team discussed the coding and the case materials until consensus was achieved. Pattern-matching logic was used to ensure internal validity (Yin, 2009).

\subsubsection{Product recall capability}

The companies studied view product recalls as critical follow-up reactions to product defects and recovery measures for product failures (Wowak and Boone, 2015). The managers explained that product recall capability includes the ability to identify the sources of defects and respond to product failures quickly.

The companies have established tracking and tracing systems throughout their supply chains. The managers commented that they could effectively identify the sources of raw materials and parts for each unit of output. As explained by the general manager, Auto could track each car to the final consumers and trace components to their suppliers to understand "when they are produced, which equipment is used in the production process, who are the front-line workers, and who are the designers." The quality manager mentioned that "we have a unique code system for each part. This code records the information of workers, suppliers, production time, product line, etc. It helps us quickly identify and trace the source of each quality problem." The implementation of the nation-wide information system built by the State Food and Drug Administration allows Pharm to register the ingredients of the drugs and record the movement of the drugs, which help Pharm trace the sources of raw materials. For each quality problem, Pharm requires suppliers to "identify the source immediately and respond to $m e$ ". Food uses ear tags to track the drugs and feeds each cow took and to keep records of all sample-testing results from milking to production. When a quality problem is detected, Food can "trace the quality problem back to the cow with the help of the ear tags". Therefore, the 
companies can access to the information that allows them to identify and trace each unit of output from production to delivery and track the sources of quality problems in the supply chains. The ability to quickly and effectively trace and track the physical and information flows in supply chains enables the companies to clarify what is going on when quality problems occur (Roth et al., 2008, Alfaro and Rabade, 2009).

The managers commented that formal processes were very important for managing product recalls. The evidence reveals that the companies have established formal processes and procedures for responding quickly to product defects. They are proactive in monitoring and handling quality problems and initiate a product recall if there are any concerns about consumer safety. For example, Auto has developed processes to respond quickly to quality complaints. Auto's general manager explained that "when problems have been found, we can quickly approach the affected consumers since we have a formal process" and that "we form a team led by the vice president to manage recall processes." The company once recalled products after it found complaints on the internet. Auto replaced and repaired the defective parts for free and provided spare cars for the affected customers. Pharm and Food have developed guidelines for determining when to recall a defective product and how to compensate customers. They recall products when they become aware of potential hazards to customers through internal inspections and before any customer reports safety incidents. Pharm's general manager explained that "we proactively recall products and have comprehensive contingency plans for dealing with recalls". Formal processes thus help the companies react early to consumer complaints and issue speedy recalls (Berman, 1999, Chen et al., 2009). Formal processes provide guidelines on when to initiate product recalls and how to coordinate product recall activities (Kumar and Schmitz, 2011, Liu et al., 2016). Therefore, the evidence suggests that tracking and traceability and formal process are the key components of companies' product recall capability.

\subsubsection{The impact of SCQM practices on product recall capability}

The evidence reveals that the companies apply quality management teamwork, supplier qualification and supplier involvement as the key SCQM practices. Quality management teams with representatives from multiple departments play critical roles in the companies' management of product recalls (Roth et al., 2008). For example, Auto's general manager mentioned that "several departments, including quality management, manufacturing, purchasing and marketing, work together to solve quality problems and manage consequent recalls". The managers agreed that cross-functional collaboration and teamwork on quality management enable them to develop processes to control quality throughout the supply chains 
(Zhang et al., 2019). Led by quality departments, the companies arrange their quality-related practices and procedures across various internal functions into synchronized and collaborative processes. Quality management teamwork thus allows employees to evaluate the impact of product recalls collaboratively and make joint decisions on reaction plans (Huo et al., 2014). Therefore, it helps the companies develop formal processes for managing product recalls (Kumar and Schmitz, 2011). In addition, quality management teamwork allows the companies to develop systems for the processing and communication of quality-related information in supply chains (Lin et al., 2005). The evidence reveals that multiple departments must work together to solve quality problems and identify the sources of the problems. For example, the general manager in Pharm mentioned that the "quality department is involved in the product design process to identify and solve design flaws." Quality management teamwork breaks down functional barriers, and employees from different departments can analyse and respond to quality problems together (Zhang et al., 2019). Thus, teamwork in quality management can improve the transparency of supply chains, facilitating the tracing and tracking of materials and products (Roth et al., 2008, Marucheck et al., 2011).

To sum up, quality management teamwork enables a company to make sense of quality problems. It provides a systematic and formal channel for employees to discuss and interpret information related to product recalls, improving tracking and traceability. The communications and interactions within the teams also facilitate companies to make joint decisions on formal process development. Therefore, the following hypothesis is proposed.

\section{H1: Quality management teamwork is positively associated with product recall capability.}

The managers agreed that supplier qualification is a key practice the companies adopted to manage suppliers and product recalls. According to Auto's general manager, Auto "conducts on-site visits to evaluate its suppliers and communicates with them about the quality issues every month." Pharm only works with suppliers who have Good Manufacturing Practices (GMP) certificates and "have compatible value on quality". On-site visits are required before placing orders with the suppliers. Food tends to collaborate with large farms that have more resources and are more capable of managing quality. Food also develops a "one hundred points" management system to evaluate suppliers. The suppliers with low points are disqualified and removed from the supply base. Quality management systems and qualifications play critical roles in the companies' supplier evaluation (Lo et al., 2007). When designing supply networks, the managers believed that the suppliers' capabilities of quality control significantly influenced their decisions in supplier evaluation. The systems and capabilities enable the companies to trace the movement of raw materials and track the sources 
of quality issues in the supply chains (Roth et al., 2008, Kaynak and Hartley, 2008). Frequent on-site audits and quality performance evaluation also help the companies promptly identify potential quality problems and improve information flows in supply chains, increasing tracking and traceability (Marucheck et al., 2011). Collaborating with suppliers that have high-quality performance and reliable quality management systems allows the companies to respond to product recalls quickly and establish guidelines and procedures to coordinate product recalls (Wowak and Boone, 2015). Thus, supplier qualification allows the companies to purposively choose partners to create supply chains with high transparency and advanced quality management capabilities and systems, which helps the companies improve their product recall capability (Yeung, 2008, Ketchen et al., 2014).

To sum up, supplier qualification allows a company to develop a supply chain environment with enhanced information quality and quantity, which improves tracking and traceability. Collaborating with suppliers that have well-established quality management procedures and systems also facilitates a company to create formal processes. Therefore, the following hypothesis is proposed.

\section{H2: Supplier qualification is positively associated with product recall capability.}

Involving suppliers in product design was viewed as an important method for developing quality competencies and managing product recalls (Zhang et al., 2019). For example, Auto partners with suppliers in the product design and involves some suppliers, such as horn and exhaust systems suppliers, in product development teams. The general manager commented that "we cooperate with our suppliers in product design by learning product ideas or blueprints from them." Pharm argues that intellectual property issues can be a concern when involving suppliers directly, and it collaborates with suppliers informally in product design through frequent communications. The managers commented that supplier involvement allowed them to leverage suppliers' resources and knowledge to design innovative products that can be easily traced and tracked. The managers also explained that involving suppliers in product design enabled them to understand threats to quality from the source and, hence, they could make product recall decisions quickly. Supplier involvement can break down the barriers between companies and suppliers and allow the companies to develop inter-organisational processes together with suppliers, which improves the information flows in the supply chains and helps the companies coordinate product recall activities (Zhang et al., 2019, Wowak and Boone, 2015). The frequent interactions associated with supplier involvement in the design processes also improve the transparency of the supply chains, which helps the companies trace the 
movement of materials and products and identify the sources of quality problems (van Echtelt et al., 2008, Flynn and Flynn, 2005). With the inputs from their suppliers, the companies can develop a deeper understanding of the materials and components, which improves tracking and traceability (Lyles et al., 2008).

To sum up, involving suppliers in product design teams provides a systematic way for companies and suppliers to interact and collaborate, which facilitates the development of interorganizational process for managing product recalls. Supplier involvement also helps companies to incorporate suppliers' knowhow and insights into new designs that can improve tracking and traceability. Therefore, the following hypothesis is proposed.

H3: Supplier involvement is positively associated with product recall capability.

The managers highlighted that supplier qualification and involvement are interrelated. Involving suppliers in new product development affects the processes and criteria used in supplier qualification (Lin et al., 2005). For example, Auto's general manager mentioned that involving suppliers in product design enabled Auto to understand its suppliers' operations and processes better, which helped it devise guidelines for supplier qualification. Food tends to involve large suppliers that have many resources and high capabilities in product development teams. It develops supplier qualification processes and procedures based on collaboration with these suppliers. These processes and procedures have been incorporated in the "one hundred points" management system and implemented for all suppliers. Pharm collaborates with suppliers that have an advanced production environment and quality control practices in new product development, and similar criteria are used in supplier qualification. To design highquality products and avoid design flaws, partnering with suppliers in product design motivates the companies to collaborate with suppliers that have reliable management systems and high operational capabilities and performances, which affects the criteria for supplier qualification (Marucheck et al., 2011, Zhang et al., 2019).

To sum up, supplier involvement enables companies to develop a better understanding of how to evaluate suppliers. It thus helps companies to create rules and standard operating procedures for supplier qualification. Therefore, the following hypothesis is proposed.

\section{H4: Supplier involvement is positively associated with supplier qualification.}

The evidence suggests that quality management teamwork plays a crucial role in facilitating supplier qualification and involvement (Huo et al., 2014). For example, Auto's general manager commented that "using teamwork in quality management builds a foundation for supplier quality management." Teamwork in quality management enables Auto to create an integrated interface to collaborate with suppliers on quality improvement, which can 
improve "the influence on my suppliers to improve my (Auto's) quality." The managers in the companies all agreed that using teams including employees from different departments, such as manufacturing, marketing and purchasing, to solve quality problems and in quality improvement projects allowed them to develop a common understanding of the expectations for suppliers (Foster, 2008, Song et al., 2017). Intensive communications and collaboration within the teams allow the managers to incorporate opinions from various departments, which helps the companies achieve agreement on the criteria and procedures for supplier qualification (Zhang et al., 2019). In addition, quality management teamwork provides an integrated interface that facilitates the communications and interactions between suppliers and companies and allows them to develop inter-organisational processes (Flynn and Flynn, 2005). It also helps the companies leverage suppliers' innovation capabilities and acquire valuable resources from them, facilitating the involvement of the suppliers in product design (van Echtelt et al., 2008). Quality management teamwork can produce knowledge that enhances product quality and avoids design flaws, which is useful for improving the procedures and criteria for supplier qualification and encouraging the companies to involve their suppliers in design processes (Huo et al., 2014, Zhang et al., 2019).

To sum up, quality management teamwork allows employees to jointly build their understandings and interpretations of quality management which form a basis for supplier management. It facilitates internal quality integration, and hence allows companies to devise consistent processes for supplier qualification. Quality management teamwork can also produce an integrated interface for cooperating and collaborating with suppliers, promoting supplier involvement. Therefore, the following hypotheses are proposed.

H5: Quality management teamwork is positively associated with supplier qualification.

H6: Quality management teamwork is positively associated with supplier involvement.

The research framework and proposed hypotheses are provided in Figure 1.

$$
\ll<<<\text { Insert Figure } 1 \text { about here }>>>>>>
$$

\subsection{Quantitative survey findings}

Structural equation modelling (SEM) is used to test the hypotheses. SEM estimates are generated using the AMOS programme with the maximum likelihood estimation method. The model fit indices are $\chi^{2}(245)=417.547, \mathrm{CFI}=0.943, \mathrm{TLI}=0.930$ and $\mathrm{RMSEA}=0.042$, indicating that the model can be accepted (Hu and Bentler, 1999). The results of the hypotheses testing are presented in Figure 2. We find that quality management teamwork $(b=0.466, p<0.01)$ and supplier qualification $(b=0.378, p<0.01)$ are positively associated with product recall capability. Hence, $\mathrm{H} 1$ and $\mathrm{H} 2$ are supported. However, the direct effect of supplier involvement 
on product recall capability is not significant. Hence, H3 is not supported. The results also show that supplier involvement is positively associated with supplier qualification $(b=0.235$, $p<0.01)$, and quality management teamwork enhances both supplier qualification $(b=0.417$, $p<0.01)$ and supplier involvement $(b=0.341, p<0.01)$. Therefore, H4, H5 and H6 are all supported. In addition, the findings reveal that Auto significantly affects $(b=-0.248, p<0.01)$ product recall capability, while the effects of other control variables are not significant.

\section{$<<<<$ Insert Figure 2 about here $>>>>>>$}

We further examine the joint effects of quality management teamwork, supplier qualification and supplier involvement on product recall capability using the SPSS PROCESS macro and the bias-corrected bootstrapping method with a 95\% confidence level and 5000 resamples (Preacher and Hayes, 2008). The results show that the indirect effect of supplier involvement on product recall capability through supplier qualification is 0.058 , and the biascorrected $95 \%$ confidence interval of the indirect effect is $(0.035,0.091)$. The indirect effect of quality management teamwork on product recall capability through supplier qualification is 0.129 , and the bias-corrected $95 \%$ confidence interval of the indirect effect is $(0.084,0.192)$. Therefore, the impact of supplier involvement on product recall capability is fully mediated by supplier qualification, and supplier qualification partially mediates the effect of quality management teamwork on product recall capability.

\section{Discussion and conclusion}

\subsection{Product recall capability and SCQM: A sensemaking perspective}

Using the sensemaking perspective, this study finds that product recall capability includes tracking and traceability and formal process. Product failures disrupt manufacturers' operations and hence trigger sensemaking (Marucheck et al., 2011, Wowak and Boone, 2015). Action is the central focus, and interpretation is the core phenomenon in sensemaking (Maitlis and Christianson, 2014). Tracking and traceability enable a manufacturer to obtain information from the supply chain environment to understand the situations of product recalls and answer the question "what's going on here?" (Weick et al., 2005). Formal processes can serve as a springboard into action to respond to product recalls and help a manufacturer answer the question "now what should I do?" (Weick et al., 2005). Therefore, product recall capability allows a manufacturer to answer the key questions of sensemaking, which enables the manufacturer to make sense of product failures (Maitlis and Christianson, 2014). In addition, tracking and traceability enhance the speed, quality and quantity of information flows in supply chains, which enables manufacturers to obtain and interpret cues from the environment to 
address the uncertainty and ambiguity associated with product recalls (Weick, 1995). Formal processes enable a manufacturer to react to product recalls using structured approaches and provide employees with a scheme that makes it possible for them to act (Weick, 1995). Therefore, the combination of tracking and traceability and formal process captures the interplay of action and interpretation. As a result, product recall capability enables employees to make sense of product defects collectively by providing consensual interpretations and courses of action (Wowak and Boone, 2015).

Organizational sensemaking is fundamentally a social process (Weick, 1995). Teamwork can break down barriers between departments, which helps employees build lateral relations for sharing information and developing social capital (Zhang et al., 2019). Employees can thus interpret product recalls and the supply chain environment through interactions with colleagues and act collectively. The use of teams also facilitates joint problem solving and decision making by bringing together the diverse points of view of individual team members. Therefore, teamwork enhances employees' abilities to appreciate the perspectives of others and facilitates collective sensemaking because employees can exchange provisional understandings and agree on interpretations and actions, reducing information equivocality (Maitlis and Christianson, 2014).

Manufacturers may obtain information about product recalls from the supply chain environment with varying levels of equivocality (Weick, 1979). Partnering with the right suppliers who have high commitment and can manage quality enables manufacturers to develop cooperative and responsive supply networks, which improves their capabilities to process and interpret information (Huo et al., 2014). Collaborating with suppliers who have reliable quality management systems allows a manufacturer to create a supply chain environment that can provide timely and processed information that allows the manufacturer to trace the raw materials to their origins, identify the sources of quality problems and develop processes to coordinate product recall activities (Roth et al., 2008). Therefore, supplier qualification allows a manufacturer to develop an enacted environment that can reduce information equivocality and facilitate sensemaking (Maitlis and Christianson, 2014).

Supplier involvement may have mixed impact on sensemaking. Involving suppliers in new product development allows a manufacturer to create a tightly coupled supply chain (van Echtelt et al., 2008). Close and interdependent relationships between a manufacturer and suppliers indicate that changes in the manufacturer's decisions can lead to predictable changes in the suppliers' operations, facilitating enactment. As a result, supplier involvement promotes sensemaking (Maitlis and Christianson, 2014). However, supplier involvement also increases 
the complexity of manufacturers' operations and processes because the manufacturers must work closely with suppliers that may have different goals, practices, systems and cultures to coordinate decisions and operations, which increases information equivocality (Weick, 1979). The effects of enactment become unpredictable in such complex situations (Maitlis and Christianson, 2014). Although supplier involvement may enact the supply chain environment to facilitate sensemaking, it may not be able to directly enhance product recall capability because the complexity increases information equivocality, which makes sensemaking difficult.

\subsection{The impact of SCQM practices on product recall capability}

The findings reveal that SCQM is a holistic system and that internal and supplier quality management practices are interrelated (Robinson and Malhotra, 2005, Foster, 2008). Quality management teamwork allows manufacturers to leverage the knowledge and expertise of employees from different departments and to consider their voices and interests in decision making, which help the manufacturers develop congruent supplier management strategies and create an integrated interface to interact with suppliers (Zhang et al., 2019). Teamwork also helps employees jointly process information and solve problems related to supplier management, which reduces information equivocality when enacting a supply chain environment (Maitlis and Christianson, 2014). Therefore, quality management teamwork is positively associated with supplier qualification and involvement. Moreover, this study finds that supplier involvement is positively associated with supplier qualification. The result suggests that manufacturers' supplier qualification decisions are influenced by the roles played by suppliers in their operations. Supplier involvement indicates that suppliers play active roles in manufacturers' operations and that manufacturers have tightly coupled supply chains. Therefore, manufacturers must collaborate with suppliers that can cope with increasing complexity to benefit from the enacted environment for sensemaking (Weick, 1995).

The results reveal that quality management teamwork and supplier qualification are positively associated with product recall capability and that supplier involvement and quality management teamwork contribute to product recall capability indirectly through supplier qualification. The findings show that quality management teamwork and supplier qualification have synergistic effects on product recall capability development. Supplier qualification partially mediates the effects of quality management teamwork on product recall capability. Therefore, quality management teamwork enhances product recall capability both directly by facilitating collective sensemaking and indirectly by facilitating supplier qualification that enacts a supply chain environment for sensemaking (Weick, 1995, Maitlis and Christianson, 
2014). Although involving suppliers in new product development cannot directly improve product recall capability, it influences the criteria and processes used in supplier qualification. Therefore, supplier involvement encourages manufacturers to choose and collaborate with suppliers that have the capabilities and resources needed to create a supply chain environment that facilitates sensemaking (Weick, 1995). The suppliers can help the manufacturers not only develop new products but also make sense of product recalls. Although supplier involvement increases complexity, collaborating with suppliers that have reliable quality management systems allows manufacturers to obtain clear information from them. As a result, supplier qualification can reduce information equivocality and, hence, it mediates the effect of supplier involvement on product recall capability.

\subsection{Theoretical contributions}

This study contributes to the literature in two ways. First, it enhances existing knowledge on the practices that manufacturers adopt to manage quality and product recalls. Researchers have provided empirical evidence on the negative effects of product recalls on performance and how the effects are influenced by companies' strategies, operations and environment (Chen et al., 2009, Steven et al., 2014, Ni et al., 2016, Zhao et al., 2013, Hora et al., 2011, Steven and Britto, 2016). Few studies have investigated the components of product recall capability (Wowak and Boone, 2015). Using the case study method and the sensemaking perspective, this paper provides empirical evidence that product recall capability includes tracking and traceability and formal process. This study also develops a measurement scale for assessing product recall capability that has been tested for validity and reliability using a quantitative survey. The results build a foundation for researchers to empirically investigate the impact of product recall capability and the factors affecting its impact (Wowak and Boone, 2015).

Second, the findings enhance existing knowledge on the antecedents of product recall capability by linking it with SCQM practices (Foster, 2008, Steven and Britto, 2016). In addition, extant studies have shown that SCQM improves quality performance and competitiveness (Lo et al., 2007, Huo et al., 2014, Yeung, 2008). This study extends the literature by revealing the positive and joint effects of SCQM practices on product recall capability development. The results show that quality management teamwork and supplier qualification directly improve product recall capability and that quality management teamwork and supplier involvement improve product recall capability indirectly through supplier qualification. Therefore, this paper suggests that researchers consider the interrelationships among SCQM practices and their synergistic effects when investigating the performance outcomes of SCQM (Lyles et al., 2008, Roth et al., 2008). Moreover, the use of a multi-method 
approach allows this paper to combine quantitative and qualitative data collection techniques and analysis procedures to corroborate research findings on the relationships between SCQM practices and product recall capability, which increases the scientific merit of the study (Boyer and Swink, 2008, Choi et al., 2016).

\subsection{Practical implications}

This study provides guidelines for the development of product recall capability for Chinese manufacturers. First, Chinese manufacturers should develop the capabilities that allow them to trace raw materials, parts and products and track the sources of quality problems across supply chains. Systems and procedures should be created for coordinating product recall activities, and strict guidelines should be developed for determining when to recall a product. Second, Chinese manufacturers should adopt quality management teamwork to integrate internal quality management efforts. They should form multifunctional teams to solve quality problems and conduct quality improvement projects. Tools should be provided to facilitate communications and interactions among team members, and procedures should be developed to integrate team members' opinions when making decisions. Third, we suggest that Chinese manufacturers implement supplier qualification and involvement as supplier quality management practices. They should regularly conduct quality audits of suppliers' sites and use established guidelines and procedures to qualify suppliers and evaluate their performance. Chinese manufacturers should collaborate with suppliers that have reliable quality management systems. In addition, this study suggests that Chinese manufacturers cooperate with suppliers in new product development and involve them in product design teams. Managers should be aware that frequent communications with suppliers in product design are also critical for managing product quality. Fourth, managers should be aware that supplier involvement enhances product recall capability only indirectly through supplier qualification; hence, this study suggests that managers implement the two practices together to capture their joint effects. Moreover, Chinese manufacturers should apply quality management teamwork and supplier qualification and involvement simultaneously to fully reap the benefits of SCQM practices for the development of product recall capability.

\subsection{Limitations and future research directions}

This study has five limitations that open avenues for future research. First, we conduct the case study and quantitative survey in China. The findings might be influenced by China's business and institutional environments and its positions in global supply chains. Future research could validate and generalize the findings in other countries. Second, this study proposes a scale for product recall capability and tests its reliability and validity. Future studies could examine its 
psychometric properties using samples from other contexts. Third, this study focuses on internal and supplier quality management practices, which is a limitation. Future studies could investigate the impact of other SCQM practices (e.g., customer quality management) on product recall capability (Robinson and Malhotra, 2005, Zhang et al., 2019). Fourth, this study may have response and common method bias because we collect survey data from single respondents, which is a limitation (Flynn et al., 2018). Future studies could collect data from multiple respondents for different sections of the questionnaire. Fifth, this study only collects survey data from manufacturers, which is a limitation. Future studies could collect data from both suppliers and manufacturers to measure the polyadic constructs related to supply chain relationships (Flynn et al., 2018).

\section{References}

Alfaro, J.A. \& Rabade, L.A. 2009. Traceability as a strategic tool to improve inventory management: A case study in the food industry, International Journal of Production Economics, 118,104-110.

Anderson, J.C., Rungtusanatham, M. \& Schroeder, R.G. 1994. A theory of quality management underlying the Deming management method, Academy of Management Review, 19, 472-509.

Beamish, P.W. \& Bapuji, H. 2008. Toy recalls and China: Emotion vs. Evidence, Management and Organization Review, 4,197-209.

Berman, B. 1999. Planning for the inevitable product recall, Business Horizons, 42, 69-78.

Boyer, K. K. \& Swink, M. L. 2008. Empirical elephants-Why multiple methods are essential to quality research in operations and supply chain management. Journal of Operations Management, 26, 337-348.

Chen, Y., Ganesan, S. \& Liu, Y. 2009. Does a firm's product-recall strategy affect its financial value? An examination of strategic alternatives during product-harm crises. Journal of Marketing, 73, 214-226.

Crede, M. \& Harms, P. D. 2015. 25 years of higher-order confirmatory factor analysis in the organizational sciences: A critical review and development of reporting recommendations. Journal of Organizational Behavior, 36, 845-872.

Choi, T., Cheng, T. C. E. \& Zhao, X. 2016. Multi-methodological research in operations management. Production and Operations Management, 25, 379-389. 
FDA. 2009. Safety: background and definitions. https://www.fda.gov/safety/industryguidance-recalls/recalls-background-and-definitions. (accessed 02/12/2019).

Flynn, B. B. \& Flynn, E. J. 2005. Synergies between supply chain management and quality management: Emerging implications. International Journal of Production Research, 43, 3421-3436.

Flynn, B., Pagell, M. \& Fugate, B. 2018. Editorial: Survey research design in supply chain management: The need for evolution in our expectations. Journal of Supply Chain Management, 54, 1-15.

Foster, S. T. 2008. Towards an understanding of supply chain quality management. Journal of Operations Management, 26, 461-467.

Fornell, C. \& Larcker, D.F. 1981. Evaluating structural equation models with unobservable variables and measurement error. Journal of Marketing Research, 18, 39-50.

Hora, M., Bapuji, H. \& Roth, A. V. 2011. Safety hazard and time to recall: The role of recall strategy, product defect type, and supply chain player in the U.S. toy industry. Journal of Operations Management, 29, 766-777.

Huo, B., Zhao, X. \& Lai, F. 2014. Supply chain quality integration: Antecedents and consequences. IEEE Transactions on Engineering Management 61, 38-51.

Kaynak, H. \& Hartley, J. L. 2008. A replication and extension of quality management into the supply chain. Journal of Operations Management, 26, 468-489.

Ketchen Jr, D., Wowak, K.D. \& Craighead, C.W. 2014. Resource gaps and resource orchestration shortfalls in supply chain management: The case of product recalls, Journal of Supply Chain Management, 50, 6-15.

Kumar, S. \& Schmitz, S. 2011. Managing recalls in a consumer product supply chain - root causeanalysis and measures to mitigate risks. International Journal of Production Research, 49,235-253.

Lin, C., Chow, W. S., Madu, C. N., Kuei, C. \& Yu, P. 2005. A structural equation model of supply chain quality management and organizational performance. International Journal of Production Economics, 96, 355-365.

Lin, C., Kuei, C. \& Chai, K. 2013. Identifying critical enablers and pathways to high performance supply chain quality management. International Journal of Operations \& Production Management, 33, 347-370.

Liu, A. X., Liu, Y. \& Luo, T. 2016. What drives a firm's choice of product recall remedy? The impact of remedy cost, product hazard, and the CEO, Journal of Marketing, 80,79-95. 
Lo, V. H. Y. \& Yeung, A. C. L. 2006. Managing quality effectively in supply chain: A preliminary study. Supply Chain Management: An International Journal, 11, 208-215.

Lo, V. H. Y., Yeung, A. H. W. \& Yeung, A. C. L. 2007. How supply quality management improves an organization's quality performance: A study of Chinese manufacturing firms. International Journal of Production Research, 45, 2219-2243.

Lyles, M. A., Flynn, B. B. \& Frohlich, M. T. 2008. All supply chains don't flow through: Understanding supply chain issues in product recalls. Management and Organization Review, 4, 167-182.

MacKenzie, S. B. \& Podsakoff, P. M. 2012. Common method bias in marketing: Causes, mechanisms, and procedural remedies. Journal of Retailing, 88, 542-555.

Maitlis, S. \& Christianson, M. 2014. Sensemaking in organizations: Taking stock and moving forward. Academy of Management Annals, 8, 57-125.

Marucheck, A., Greis, N., Mena, C. \& Cai, L. 2011. Product safety and security in the global supply chain: Issues, challenges and research opportunities. Journal of Operations Management, 29, 707-720.

Ni, J., Flynn, B. B. \& Jacobs, F. R. 2016. The effect of a toy industry product recall announcement on shareholder wealth. International Journal of Production Research, $54,5404-5415$.

Podsakoff, P.M., Mackenzie, S.B., Lee, J.Y. \& Podsakoff, N.P. 2003. Common method biases in behavioural research: A critical review of the literature and recommended remedies. Journal of Applied Psychology, 88, 879-903.

Preacher, K. \& Hayes, A. 2008. Asymptotic and resampling strategies for assessing and comparing indirect effects in multiple mediator models. Behaviour Research Methods, 40, 879-891.

Robinson, C. J. \& Malhotra, M. K. 2005. Defining the concept of supply chain quality management and its relevance to academic and industrial practice. International Journal of Production Economics, 96, 315-337.

Roth, A. V., Tsay, A. A., Pullman, M. E. \& Gray, J. V. 2008. Unraveling the food supply chain: Strategic insights from china and the 2007 recalls. Journal of Supply Chain Management 44, 22-39.

Saunders, M., Thornhill, A. \& Lewis, P. 2009. Research methods for business students, England, Pearson Education Limited.

Smith, N.G., Thomas, R.J., \& Quelch, J.A. 1996. A strategic approach to managing product recalls. Harvard Business Review 74, 102-112. 
Song, H., Turson, R., Ganguly, A. \& Yu, K. 2017. Evaluating the effects of supply chain quality management on food firms' performance: The mediating role of food certification and reputation. International Journal of Operations \& Production Management, 37, 15411562.

Sousa, R. \& Voss, C. A. 2001. Quality management: Universal or context dependent? Production and Operations Management, 10, 383-404.

Sousa, R. \& Voss, C. A. 2002. Quality management re-visited: A reflective review and agenda for future research. Journal of Operations Management, 20, 91-109.

Stericycleexpertsolution 2019. European Recall \& Notification Index Q1 2019. https://www.stericycleexpertsolutions.co.uk/sites/stericycleexpertsolutions/files/2019 _q1.pdf (accessed 22/06/2019).

Steven, A. B. \& Britto, R. A. 2016. Emerging market presence, inventory, and product recall linkages. Journal of Operations Management, 46, 55-68.

Steven, A. B., Dong, Y. \& Corsi, T. 2014. Global sourcing and quality recalls: An empirical study of outsourcing-supplier concentration-product recalls linkages. Journal of Operations Management, 32, 241-253.

Thirumalai, S. \& Sinha, K. K. 2011. Product recalls in the medical device industry: An empirical exploration of the sources and financial consequences. Management Science, 57, 376-392.

van Echtelt, F. Wynstra, F., \& van Weele, A. J. 2008. Managing supplier involvement in new product development: A multiple case study. Journal of Product Innovation Management, 25, 180-201.

Voss, C., Tsikriktsis, N. \& Frohlich, M. T. 2002. Case research in operations management. International Journal of Operations \& Production Management, 22,195-219.

Wan, Z., Beil, D.R. \& Katok, E. 2012. When does it pay to delay supplier qualification? Theory and experiments. Management Science, 58, 2057-2075.

Weick, K. E. 1979. The social psychology of organizing, Reading, Massachusetts, AddisonWesley Publishing Company.

Weick, K. E. 1995. Sensemaking in organizations, Thousand Oaks, California, Sage Publications.

Weick, K. E., Sutcliffe, K. M. \& Obstfeld, D. 2005. Organizing and the process of sensemaking. Organization Science, 16, 409-421. 
Wood, L. C., Wang, J. X., Olesen, K. \& Reiners, T. 2017. The effect of slack, diversification, and time to recall on stock market reaction to toy recalls. International Journal of Production Economics, 193, 244-258.

Wowak, K. D. \& Boone, C. A. 2015. So many recalls, so little research: A review of the literature and road map for future research. Journal of Supply Chain Management, 51, 54-72.

Yao, L. \& Parlar, M. 2019. Product recall timing optimization using dynamic programming. International Journal of Production Economics, 210, 1-14.

Yeung, A. C. L. 2008. Strategic supply management, quality initiatives, and organizational performance. Journal of Operations Management, 26, 490-502.

Yin, R. K. 2009. Case study research: Design and methods, Thousand oaks, California, Sage Publications.

Zhang, M., Guo, H., Huo, B., Zhao, X. \& Huang, J. 2019. Linking supply chain quality integration with mass customization and product modularity. International Journal of Production Economics, 207, 227-235.

Zhao, X., Li, Y. \& Flynn, B. B. 2013. The financial impact of product recall announcements in China. International Journal of Production Economics, 142, 115-123.

Appendix I. Case description

\begin{tabular}{|l|l|}
\hline Case & Description \\
\hline Auto & $\begin{array}{l}\text { Auto is a joint-venture assembler. It strives to implement the ideology of "quality } \\
\text { first" and requires suppliers to follow the same ideology. Its products have } \\
\text { established a reputation and image of high quality and have been awarded the "Top } \\
\text { Family Vehicle" and "Top Safety Vehicle" in China. } \\
\text { Suppliers and internal production processes are two major sources of quality } \\
\text { problems. The quality department plays a unique and important role in supply chain } \\
\text { management. It qualifies each potential supplier based on the quality criteria and } \\
\text { has the power to veto candidate suppliers if they cannot meet the quality standards. } \\
\text { The quality of the key components related to safety is jointly controlled by Auto } \\
\text { and its suppliers. Auto also manages two tiers of suppliers-both its suppliers and } \\
\text { the suppliers' suppliers-to control quality. } \\
\text { Auto decided to recall over 18,000 cars in } 2010 \text { when it learned about a quality } \\
\text { problem from an internet forum. Once the recall was issued, the quality department } \\
\text { took charge of the recall process, identified the sources of the problem and worked } \\
\text { together with all related parties to solve the problem. }\end{array}$ \\
\hline Food & $\begin{array}{l}\text { Food is a dairy manufacturer. The main raw material is milk, which is sourced from } \\
\text { self-operated farms, contracted-out farms and breeding villages. Food promotes } \\
\text { higher quality standards than its competitors (e.g., regarding the amount of } \\
\text { antibiotic) and requires its suppliers to comply with these standards. It has been }\end{array}$ \\
\hline
\end{tabular}




\begin{tabular}{|c|c|}
\hline & $\begin{array}{l}\text { awarded the "Food Safety: Top } 10 \text { Enterprises in China" and "Food Safety: The } \\
\text { Most Socially Responsible Enterprises in China". } \\
\text { The quality risks come from both the quality of the raw milk and the production } \\
\text { processes. Food has taken an active role in supply chain management. For example, } \\
\text { it improves control over raw materials by vertically integrating with farmers. It } \\
\text { provides technical support to farms, such as fertilization techniques, to improve the } \\
\text { quality of milk. }\end{array}$ \\
\hline Pharm & $\begin{array}{l}\text { Pharm produces Chinese traditional patent medicine. It believes quality is vital for } \\
\text { survival. The quality of drugs is mainly determined by the quality of raw materials. } \\
\text { To increase the quality control over the raw materials, Pharm actively manages its } \\
\text { supply chains and forms strategic alliances with suppliers. It also provides suppliers } \\
\text { with scientific knowledge about how to plant and offers training. } \\
\text { Pharm uses the information system provided by the State Food and Drug } \\
\text { Administration to track the pharmaceutical products and raw materials. If a drug } \\
\text { has any quality problem, Pharm can easily trace the source of the problem, and track } \\
\text { the flow of drugs. Pham has also applied the Good Manufacturing Practices to } \\
\text { manage the production and logistics processes. }\end{array}$ \\
\hline
\end{tabular}

Appendix II. Data collection

\begin{tabular}{|c|l|l|}
\hline Case & Date & Interviewees \\
\hline Food & $\begin{array}{c}\text { August } \\
\text { One manufacturer and one supplier were interviewed. The } \\
\text { interviewees of the manufacturer included one general manager } \\
\text { and one quality manager. The general manager had been working } \\
\text { in the industry for 8 years and at the company as a general manager } \\
\text { for 3 years, while the quality manager had been working at the } \\
\text { company for 5 years. For the supplier, one quality manager who } \\
\text { had been working in the company for 10 years (4 years as quality } \\
\text { manager) was the interviewee. All the interviewees had } \\
\text { encountered the "melamine milk powder event" in 2008. They } \\
\text { were very familiar with quality and product recall management. }\end{array}$ \\
\hline Pharm & $\begin{array}{l}\text { September } \\
\text { December }\end{array}$ & $\begin{array}{l}\text { One manufacturer and one supplier were interviewed. The } \\
\text { interviewee of the manufacturer was the general manager. One } \\
\text { purchasing manager and one quality manager of the supplier were } \\
\text { interviewed. The general manager of the manufacturer had been } \\
\text { working at the company over 20 years. She had managed two } \\
\text { recalls in the past 5 years and had overseen the quality department. } \\
\text { The purchasing manager and the quality manager of the supplier } \\
\text { were responsible for the quality of the products supplied to the } \\
\text { manufacturer. The two managers had been working with the } \\
\text { manufacturer to recall products because of a high level of } \\
\text { bacterium, and they helped the manufacturer quickly identify the } \\
\text { source of the problem. }\end{array}$ \\
\hline
\end{tabular}




\begin{tabular}{|c|c|c|}
\hline Auto & $\begin{array}{l}\text { January } \\
2011 \\
\text { September } \\
2011\end{array}$ & $\begin{array}{l}\text { One manufacturer and four suppliers (i.e., exhaust pipe supplier, } \\
\text { cable system supplier, brake supplier and klaxon supplier) were } \\
\text { interviewed. The interviewees of the manufacturer included one } \\
\text { general manager and one quality manager. One quality manager } \\
\text { from each of the first three suppliers and one general manager } \\
\text { from the other supplier were interviewed. All interviewees had } \\
\text { been working in their current positions for over } 3 \text { years and, hence, } \\
\text { they had good knowledge of the quality management systems and } \\
\text { practices of their companies. All interviewees had first-hand } \\
\text { experience of at least one product recall, which ensured that they } \\
\text { were familiar with product recall management. }\end{array}$ \\
\hline & \multicolumn{2}{|c|}{$\begin{array}{l}\text { 1. Please describe the structure of your supply chains. } \\
\text { 2. Please outline the supply chain management practices and techniques used } \\
\text { by your company. } \\
\text { 3. Please outline the quality management practices and techniques used by your } \\
\text { company. } \\
\text { 4. What roles does quality play in the supply chain design? } \\
\text { 5. Has your company experienced any quality issues recently? If yes, can you } \\
\text { give us some examples? What are the causes of the quality issues? } \\
\text { 6. What roles does quality department play in your company's internal } \\
\text { operations? } \\
\text { 7. Does the quality department collaborate with other departments, and if so, } \\
\text { through what means? Can you give us some examples? } \\
\text { 8. Does your company collaborate with supply chain partners to improve } \\
\text { quality, and if so, through what means? Can you give us some examples? } \\
\text { 9. How do supply chain partners influence product quality? } \\
\text { 10. Does quality management influence supply chain management practices? If } \\
\text { yes, through what means? Can you give us some examples? } \\
\text { 11. Has your company recalled any products recently? If yes, can you give us } \\
\text { some examples? } \\
\text { 12. Please outline the product recall processes. } \\
\text { 13. Please describe how product recalls are managed. } \\
\text { 14. What roles do internal departments play in product recalls? } \\
\text { 15. What roles do supply chain partners play in product recalls? }\end{array}$} \\
\hline
\end{tabular}

Appendix III. Measurement items

\begin{tabular}{|l|l|}
\hline Product recall capability & \\
\hline Tracking and traceability C.R. $=0.838$ alpha=0.739 $A V E=0.568^{+}$ & $.828^{++}$ \\
\hline We can identify and trace each unit of our output from production to delivery. & .836 \\
\hline $\begin{array}{l}\text { We can effectively identify the sources of all raw materials and parts for each } \\
\text { unit of output. }\end{array}$ & .707 \\
\hline $\begin{array}{l}\text { We can promptly identify the sources of quality problems in our supply } \\
\text { chains. }\end{array}$ & .623 \\
\hline $\begin{array}{l}\text { We have access to the information that allows tracking the sources of quality } \\
\text { problems in supply chains. }\end{array}$ & .863 \\
\hline Formal process $C . R .=0.857$ alpha $=0.746 A V E=0.667$ & \\
\hline $\begin{array}{l}\text { There are standardized procedures for initiating a product recall if there are } \\
\text { any concerns about consumer safety. }\end{array}$ & \\
\hline
\end{tabular}




\begin{tabular}{|l|l|}
\hline $\begin{array}{l}\text { We have established systems and processes for coordinating product recall } \\
\text { activities. }\end{array}$ & .819 \\
\hline $\begin{array}{l}\text { Our company has strict guidelines for determining when we should recall a } \\
\text { defective product. }\end{array}$ & .766 \\
\hline Quality management teamwork C.R.=0.880 alpha=0.829 AVE=0.595 & \\
\hline $\begin{array}{l}\text { We get all team members' opinions and ideas before making a quality } \\
\text { improvement decision. }\end{array}$ & .748 \\
\hline Our company forms multifunctional teams to manage quality. & .786 \\
\hline $\begin{array}{l}\text { Many quality problems have been solved through multifunctional teams in } \\
\text { our company. }\end{array}$ & .798 \\
\hline Problem-solving teams have helped improve quality in our company. & .791 \\
\hline $\begin{array}{l}\text { Team members easily communicate with each other in solving quality } \\
\text { problems. }\end{array}$ & .731 \\
\hline Supplier qualification C.R.=0.881 alpha=0.708 AVE=0.652 & .798 \\
\hline We regularly conduct quality audits of our suppliers' sites. & .755 \\
\hline $\begin{array}{l}\text { We regularly evaluate the quality performance of our suppliers, following } \\
\text { established guidelines and procedures. }\end{array}$ & .696 \\
\hline $\begin{array}{l}\text { We follow a well-established procedure to qualify our suppliers before } \\
\text { placing orders with them. }\end{array}$ & .680 \\
\hline We select suppliers that have a reliable quality management system. & .800 \\
\hline Supplier involvement C.R.=0.848 alpha=0.730 AVE=0.651 & .799 \\
\hline We partner with our suppliers in the design of our products. & .821 \\
\hline $\begin{array}{l}\text { We have frequent communications with our suppliers during the product } \\
\text { design phase. }\end{array}$ & \\
\hline We involve our suppliers in our new product design teams. \\
\hline $\begin{array}{l}\text { Note: }{ }^{+} \text {. } \text {.: composite reliability; alpha: } \text { Cronbach's alpha; } \text { AVE: average variance extracted. } \\
++ \text { All item loadings are significant at the }<<0.01 \text { level. }\end{array}$ \\
\hline
\end{tabular}

Appendix IV. Case findings

\begin{tabular}{|c|c|c|}
\hline Case & Product recall capability & SCQM practice \\
\hline Auto & $\begin{array}{l}\text { - An information system is used to } \\
\text { trace components and parts sourced } \\
\text { from suppliers. } \\
\text { - When problems are found, Auto can } \\
\text { quickly identify the affected } \\
\text { consumers since it has a system to } \\
\text { record the physical flows in the } \\
\text { supply chains. } \\
\text { - Auto is proactive in recalls, and it } \\
\text { collects information about quality } \\
\text { through multiple channels. } \\
\text { - Product recalls are managed by teams } \\
\text { led by top-level managers. }\end{array}$ & $\begin{array}{l}\text { - Internal departments collaborate to } \\
\text { solve quality problems and manage } \\
\text { product recalls. } \\
\text { - Multifunctional teams have been } \\
\text { widely used in supply chain } \\
\text { management. } \\
\text { - Auto selects suppliers based on the } \\
\text { supplier's qualification and } \\
\text { management system. } \\
\text { - Every month, Auto conducts on-site } \\
\text { visits to evaluate its suppliers and } \\
\text { provides feedback on quality } \\
\text { performance. } \\
\text { - Auto collaborates with suppliers in } \\
\text { new product development to reduce } \\
\text { design flaws. }\end{array}$ \\
\hline Food & $\begin{array}{l}\text { Each cow has a unique ear tag to track } \\
\text { the drugs and the feeds it receives. }\end{array}$ & $\begin{array}{l}\text { - Food promotes higher quality } \\
\text { standards than its competitors, }\end{array}$ \\
\hline
\end{tabular}




\begin{tabular}{|c|c|c|}
\hline & $\begin{array}{l}\text { - Food has developed standard } \\
\text { processes for collecting information } \\
\text { from retailers. } \\
\text { - Food has formal processes to } \\
\text { determine the compensation to } \\
\text { consumers when quality problems } \\
\text { occur. }\end{array}$ & $\begin{array}{l}\text { regarding aspects such as the amount of } \\
\text { antibiotic given, and requires farms and } \\
\text { farmers to comply. } \\
\text { - Food tends to source raw materials } \\
\text { from large farms rather than from } \\
\text { individual farmers. } \\
\text { - Food uses a "one hundred points" } \\
\text { management system to evaluate farms. } \\
\text { - Food regularly conducts on-site audits } \\
\text { on the farms. }\end{array}$ \\
\hline Pharm & $\begin{array}{l}\text { - Pharm uses the National Drug } \\
\text { Administration System to track } \\
\text { products. } \\
\text { - All drugs, including the ingredients } \\
\text { and their suppliers, are registered } \\
\text { before production. } \\
\text { - Pharm proactively recalls products } \\
\text { and has developed plans for } \\
\text { managing product recalls. }\end{array}$ & $\begin{array}{l}\text { - The quality department is involved in } \\
\text { product design process. } \\
\text { - Pharm frequently communicates with } \\
\text { suppliers when developing new } \\
\text { products. } \\
\text { - Pharm collaborates with suppliers that } \\
\text { have compatible values regarding } \\
\text { quality. } \\
\text { - Quality-related criteria, such as } \\
\text { supplier qualification (e.g., GMP } \\
\text { certificate), production environment } \\
\text { and quality control process, play a } \\
\text { critical role in supplier qualification. } \\
\text { - Pharm evaluates suppliers based on } \\
\text { their quality performance. } \\
\text { - On-site visits are frequently conducted } \\
\text { in supplier qualification. }\end{array}$ \\
\hline
\end{tabular}

